\title{
Lipid Disturbances in Psoriasis: An Update
}

\author{
Aldona Pietrzak, ${ }^{1}$ Anna Michalak-Stoma, ${ }^{1}$ Grażyna Chodorowska, ${ }^{1}$ \\ and Jacek C. Szepietowski² \\ ${ }^{1}$ Department of Dermatology, Venereology and Paediatric Dermatology, Medical University of Lublin, ul. Radziwillowska 13, \\ 20-080 Lublin, Poland \\ ${ }^{2}$ Department of Dermatology, Venereology and Allergology, Wrocław Medical University and Ludwik Hirszfeld Institute of \\ Immunology and Experimental Therapy, Polish Academy of Sciences, ul. R. Weigla 12, 53-114 Wrockaw, Poland \\ Correspondence should be addressed to Jacek C. Szepietowski, jszepiet@derm.am.wroc.pl
}

Received 12 April 2010; Accepted 10 June 2010

Academic Editor: Giuseppe Valacchi

Copyright ( $\odot 2010$ Aldona Pietrzak et al. This is an open access article distributed under the Creative Commons Attribution License, which permits unrestricted use, distribution, and reproduction in any medium, provided the original work is properly cited.

Psoriasis is a common disease with the population prevalence ranging from $2 \%$ to $3 \%$. Its prevalence in the population is affected by genetic, environmental, viral, infectious, immunological, biochemical, endocrinological, and psychological factors, as well as alcohol and drug abuse. In the recent years, psoriasis has been recognised as a systemic disease associated with numerous multiorgan abnormalities and complications. Dyslipidemia is one of comorbidities in psoriatic patients. Lipid metabolism studies in psoriasis have been started at the beginning of the 20th century and are concentrated on skin surface lipids, stratum corneum lipids and epidermal phospholipids, serum lipids, dermal low-density lipoproteins in the psoriatic skin, lipid metabolism, oxidative stress and correlations between inflammatory parameters, lipid parameters and clinical symptoms of the disease. On the basis of the literature data, psoriasis can be described as an immunometabolic disease.

\section{Introduction}

Psoriasis is a common disease affecting, as presumed, approximately 120-180 million people worldwide [1]. Around 150,000 new cases of psoriasis are reported annually. There are fewer reports on the incidence of psoriasis, but in recent studies an increasing trend over the last 3 decades was shown $[1,2]$. The population prevalence of psoriasis has been reported to range from $2 \%$ to $3 \%$. However, in some countries there is a higher prevalence rate for psoriasis, for example in Kazakhstan, Trinidad and Tobago, Paraguay, Kenya, Tanzania, Egypt, and Kuwait [3]. Four hundred people die annually from psoriasis-related causes in the Unites States [1]. Psoriasis prevalence in the population is affected by genetic, environmental, viral, infectious, immunological, biochemical, endocrinological, and psychological (trauma, stress) factors as well as alcohol and drug abuse $[4,5]$.

In the recent years, psoriasis has been recognised as a systemic disease associated with numerous multiorgan abnormalities and complications. In psoriatic patients an increased risk of cardiovascular abnormalities, hypertension, dyslipidemia, atherosclerosis, diabetes mellitus type 2, obesity, chronic obturative pulmonary disease, cerebral stroke, osteoporosis, cancer, and depression was noticed [6-8].

Lipid metabolism research studies in psoriasis have been started at the beginning of the 20th century from the quantitative analysis of serum cholesterol in psoriatic patients [9]. The abnormal fat metabolism was considered to be an important factor in the etiopathogenesis of psoriasis. Grütz and Burger examined the development of psoriatic skin manifestations as a symptom comparable to xanthomatosis $[9,10]$. Melczer found changes in the composition of phospholipids in psoriatic foci and suggested that inflammation, congestion, and parakeratosis resulted from lipid deposition in the reticular-endothelial system [11]. It was also suggested that continuous separation of psoriatic scales caused the permanent loss of lipids which might affect serum lipid abnormalities $[11,12]$. Lipid metabolism is a complex process which takes place in different human organs and peripheral blood (Figure 1) [13]. Its disturbances in psoriasis need further studies to be fully elucidated. There are some 
new methods for diagnosis of cholesterol in the healthy skin available; however its exact usefulness should be carefully recognised $[14,15]$.

Nowadays the studies are concentrated on the skin surface lipids, epidermal lipids (including stratum corneum lipids, and epidermal phospholipids), serum lipids, dermal low-density lipoproteins in the psoriatic skin, lipid metabolism, oxidative stress and correlations between inflammatory parameters, lipid parameters, and clinical symptoms of the disease (Figure 2) [10-12, 16-19]. The aim of this study is to present an update of the lipid studies in psoriasis on the basis of the literature review.

\section{Skin Surface and Epidermal Lipids}

The stratum corneum consists of corneocytes and intracellular lipids, mainly ceramides, sterols, and free fatty acids which form the barrier for diffusion of substances into the skin [20-23]. The lipids are organised into multilamellar intercellular membranes derived from glycerophospholipids, glucocerebrosides, sphingomyelin of the stratum granulosum-stratum corneum interface [23, 24]. Then the precursors are converted to ceramides and free fatty acids by the hydrolytic enzymes $[25,26]$. In psoriasis, alterations in ceramide content have been demonstrated [27] and abnormal lipid structures reported [28]. Total lipids, phospholipids, triacylglycerols, and cholesterol were found to increase both in blood and in epidermis of psoriatic patients $[29,30]$. The proportion of an esterified fraction decreased mainly in the normally appearing epidermis areas, especially in severe psoriasis [31]. In the gas liquid chromatography, significantly lower spectrum of short-chain fatty acids (SCFAs) levels were detected in both psoriatic and uninvolved areas [32]. The correlation was found between increased levels of free and total cholesterol as well as phospholipids in the epidermis and the severity of psoriasis $[31,32]$.

The main features of the corneous layer observed under the scanning electron microscope include widened intracellular spaces, lack of resistant intercellular junctions, impaired intracellular adhesion, which may result in markedly abnormal cholesterol homeostasis $[33,34]$. In the lipid thin-layer chromatography, an increased amount of total phospholipids was found in the involved psoriatic epidermis whereas the decrease of phosphatidylserine and the increase of phosphatidylinositol were observed in psoriatic lesions and in the lesion-free epidermis [35].

Lacroix demonstrated significant amount of cholesterol in scaly plagues and in serum. He suggested that psoriasis might be the form of cholesterol elimination through the skin [9]. The regulation of cellular cholesterol metabolism is already fully developed in the foetal life. The maintenance of its steady cellular levels is an important element of cellular and systemic homeostasis. It is already known that this homeostasis is disturbed in psoriasis [10]. Every day about $85 \mathrm{mg}$ of cholesterol is secreted through the healthy skin. In psoriasis, the patients lost daily 12-23.5-fold more lipids with the scales than healthy subjects $[18,36,37]$.

\section{Serum Lipids}

Serum lipids levels were examined in many different groups of psoriatic patients in comparison to relevant healthy controls [9-11, 16, 18, 38-48]. The blood lipid results are considerably dependent on group matching (age, gender, and ethnic and cultural factors). In most of the studies, a statistically significant elevated level of total cholesterol (TC), low-density lipoprotein (LDL) cholesterol and/or triglycerides (TG) in psoriatic patients was demonstrated comparing to a healthy control group $[11,16,18,39,40,43-$ 47, 49-52]. Moreover, there was a decrease of high density lipoprotein (HDL) cholesterol in the serum of psoriatic patients [43, 48, 50-53]. Only in a few studies no differences in lipid serum levels between psoriatic patients and healthy controls were observed [38, 42, 54].

Nowadays there is an increased interest in HDL cholesterol, because clinical and epidemiological studies showed an inverse relationship between the level of HDL and the development of atherosclerosis [55]. HDL is a very important factor in reverse cholesterol transport (RCT). It takes part in the transport of cholesterol produced or accumulated in the peripheral tissues to the liver or other steroidogenic tissues and exerts the antioxidant, anti-inflammatory, antithrombotic and fibrinolytic action [55]. It should be underlined that neither HDL nor LDL is "bad cholesterol," because both are essential for the proper transport of cholesterol (Figure 3).

Results of the studies present a decrease of cholesterol and phospholipids levels connected with HDL fraction independently of psoriasis severity and duration [36]. In psoriasis, a decrease of HDL synthesis and HDL structural changes can be observed, due to various biochemical disturbances, such as abnormalities of receptor function, changes of hepatic structure and function, activity changes of hepatocyte membranes, impaired RCT, esterification, and lipases [36]. It can be hypothesised that HDL structural changes are caused by a decrease of cholesterol and phospholipids level as well as an increase of apolipoprotein A (apoA) concentration in the HDL coat. So far, all the studies were based on the quantitative evaluation of lipids in the psoriatic patient serum and epidermis. Further studies are needed to specify the role of disturbances of HDL structure and composition as well as connections between lipid abnormalities and the immune response in psoriasis.

The studies concerning the concentration of serum phospholipids in the psoriatic patients present different results. A decrease of concentration of total phospholipids, as well as phosphatidylethanolamine, lecithin, the lecithin : cholesterol ratio and linolenic acid, docosatetraenoic acid, docosapentaenoic acid, and docosahexaenoic acid in the serum was observed [57-61]. There was also an increased level of some fractions of serum phospholipids (e.g., lysolecithin) and palmitic acid, palmitoleic acid, and dihomo- $\gamma$-linolenic acid (DHLA) [57, 58, 62-64]. Some reports, however, do not present any differences in the level of serum phospholipids between psoriatic patients and healthy control group [65]. Our results did not show any statistically significant differences in the level of total phospholipids, but the decreasing 


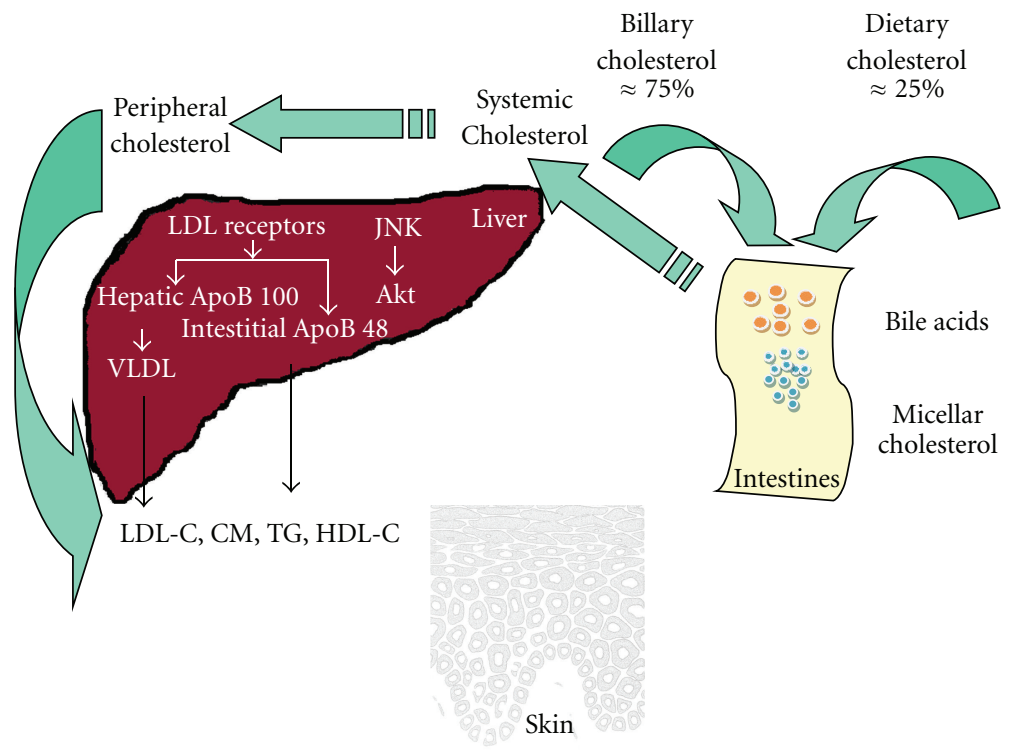

FIGURE 1: Cholesterol trafficking in human organism. CM: chylomicrones, HDL-C: high-density lipoproteins cholesterol, LDL-C: lowdensity lipoproteins cholesterol, VLDL-C: very low-density lipoproteins cholesterol, TG: triglycerides, JNK: Janus-family tyrosine kinase, and Akt: kinase Akt. The figure is adapted after permission from [13]. The complete electronic version of this article can be found online at: http://www.lipidworld.com/content/8/1/41.

tendency of its level was seen in both normolipidemic and hyperlipidemic patients [10].

\section{Apolipoproteins}

Apolipoproteins are the protein part of lipoproteins, and their composition is specific for each lipoprotein. They have a different molecular structure, amino acid composition, and antiatherosclerotic properties. In psoriatic patients, different results concerning apolipoproteins apoA1, apoB, and apoE were presented [16, 41, 66, 67]. Apolipoprotein A1 has been immunocytochemically detected at the psoriatic skin dermoepidermal junction, vascular walls, and the perivascular region of papillary dermis. Apolipoprotein B100 and apolipoprotein $\mathrm{E}$ were observed intracellularly both in normal epidermis and psoriatic epidermis, and they were also detected in parakeratotic regions in the horny layer [68].

ApoAl plays the main part in the reverse cholesterol transport from the peripheral cells to the liver. Its decreased level has an influence on the higher risk of atherosclerosis development [69]. ApoA2 stabilizes the HDL structure and is considered as the lecithin: cholesterol acetyltransferase (LCAT) inhibitor. Its role concerning atherosclerosis is controversial, because it was shown that apoA1 impaired the inflow of cholesterol from adipocytes to the extracellular space [70]. Elevated levels of apolipoproteins A1 and A2 accompany the intake of alcohol. The level of apoA 1 increases also in familiar hyperproteinemia, in pregnancy, during estrogen therapy, and during physical exercise.

Elevated levels of apolipoprotein B are associated with the increased risk of atherosclerosis, due to its role in the cholesterol accumulation in the endothelium, which initiates the atheromatous process. Apo B elevated levels are observed in the hyperlipidemia type IIa, IIb, IV, and V, in nephritic syndrome, pregnancy, familiar hyperapo-ß-lipoproteinemia, biliary obstruction, smokers, and dialyzed patients on treatment with diuretics ß-blockers, cyclosporine, or glucocorticoids [71].

Apolipoprotein C3 (apoC3) is suggested to inhibit lipoprotein lipase $[72,73]$ and hepatic triglyceride lipase [74], enzymes responsible for the clearance of triglyceride rich particles from the plasma. Furthermore, apoC3 was shown to inhibit the hepatic uptake of triglyceride rich particles [75]. Apo C3 also appears to interfere with HDL receptor-mediated uptake of lipoproteins. It is known that an increase in apoC3 levels induces the development of hypertriglyceridemia.

In most studies, elevated levels of apoA1, apoB $[16,43]$, apoC3, and apoE [41, 76-78] were detected in the serum of psoriatic patients compared to the healthy control group. However, there are also contrary results showing decreased levels of apolipoproteins [79]. Many authors did not show any differences in apoA1, apoA2, and apoB levels between psoriatic patients and the control group [10, 76, 80]. It was also reported that apoA1 sequestration in the inflamed tissues might lead to reduced HDL-C serum levels and thus increase the risk of cardiovascular disease in psoriatic patients [81].

Apolipoprotein E (ApoE) is a glycoprotein involved in the regulation of triglycerides and low-density lipoprotein (LDL) levels [67]. ApoE can modulate mitogen-activated Tlymphocyte proliferation in vitro and provides protection against some infections $[82,83]$. The role of the apoE gene in psoriasis was suggested, because in psoriatic skin there is the downregulation of $\mathrm{ApoE}$ expression and the normalization of ApoE levels precedes clinical improvement [67]. Furthermore, in a Japanese population the epsilon 2 allele was found to be significantly more frequent in 


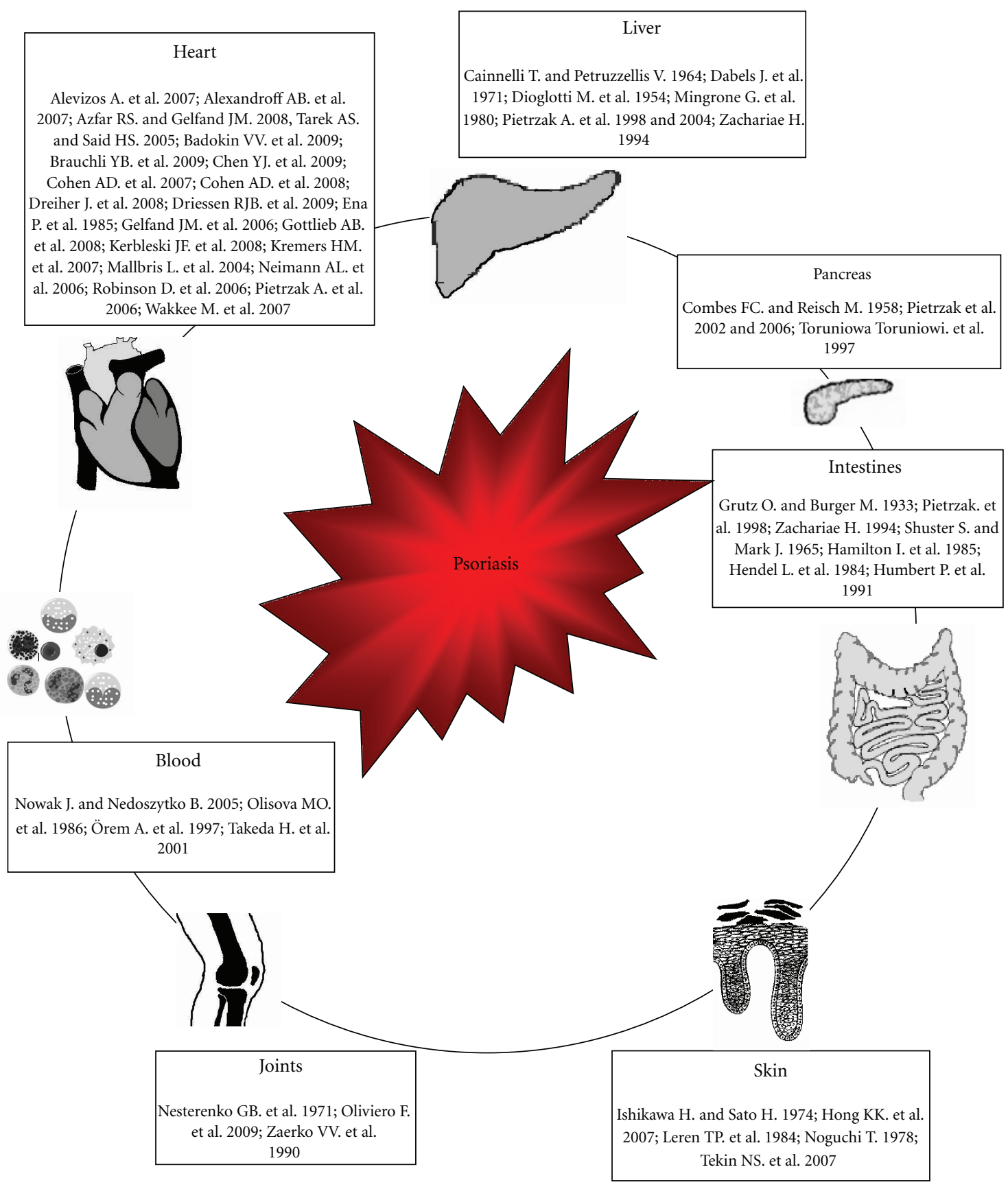

FIGURE 2: Influence of the psoriasis associated dyslipidemia on human organs. This figure is based (after permission) on the figure from [19].

psoriatic patients than in controls, suggesting that there may be a relationship between these particular alleles and development of psoriasis [84]. It is believed that the epsilon 4 allele could be a risk factor for developing a severe form of psoriasis [85].

\section{Oxidative Stress}

Reactive oxygen species (ROSs) such as hydroxyl radical $\left(\mathrm{HO}^{\bullet}\right)$, peroxyl radicals $\left(\mathrm{ROO}^{\bullet}\right)$, superoxide anion
$\left(\mathrm{O}_{2}{ }^{\bullet-}\right)$, hydrogen peroxide $\left(\mathrm{H}_{2} \mathrm{O}_{2}\right)$, nitrogen oxide $\left(\mathrm{NO} \mathrm{O}^{\bullet}\right)$, and hypochlorous acid $(\mathrm{HOCl})$ are constantly produced as a result of metabolic reactions in living systems [86]. Oxidative stress may be defined as an imbalance between cellular production of ROS and antioxidant defence mechanisms. It leads to oxidative damage of lipids and proteins contributing to barrier integrity, which is essential for healthy skin conditions $[18,87,88]$. The skin antioxidant system consists of a network of both enzymatic (glutathione peroxidase (GSH-Px), catalase (CAT), superoxide dismutase (SOD), and paraoxonase $(\mathrm{PON} 1)$ ) and nonenzymatic 

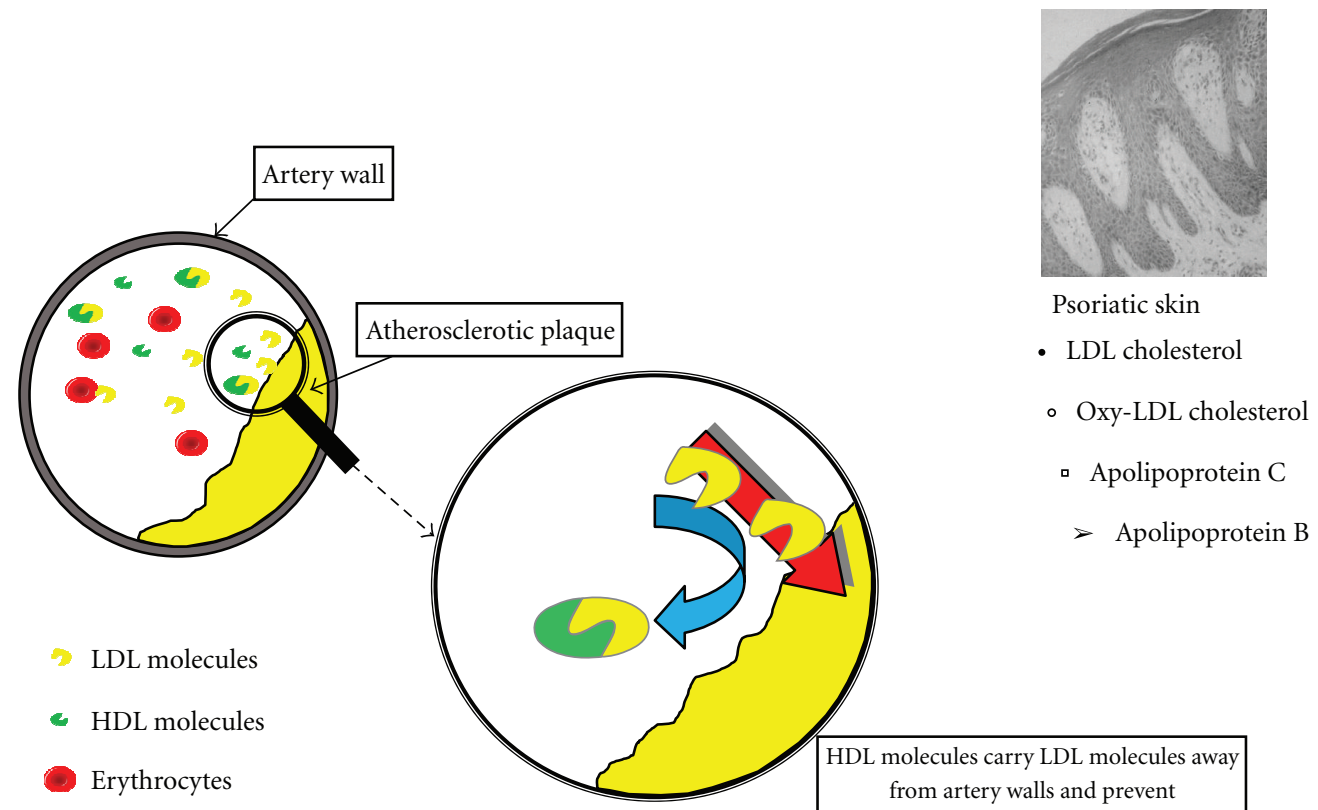

FIGURE 3: Lipoprotein replacement in circulation from artery walls and peripheral blood into psoriatic skin lesions. Based and modified with permission from figures from [56]. Available from http://www.biolsci.org/v05p0474.htm.

antioxidants. Nonenzymatic antioxidants (glutathione, $\beta$ carotene, ascorbic acid, and tocopherols) present in cells are regarded as protectors against the lipid peroxidation [88].

Increased production of oxygen metabolites, overwhelming the antioxidant capacity of the body, is an important feature in psoriasis [87]. Early and active psoriatic lesions are characterized by the intraepidermal penetration of activated polymorphonuclear leucocytes which leads to ROS production provided by NADPH oxidase and proteolytic enzymes [88]. The production of ROS can be indirectly assessed by the levels of lipid peroxidation products such as lipid hydroperoxide (LHP), malondialdehyde (MDA), oxidized low-density lipoprotein (ox-LDL), and thiobarbituric acid (TBA) [87]. Patients with psoriasis exhibit increased concentrations of MDA $[51,87,89,90]$ and ox-LDL [18] in the tissues and higher levels of TBA $[43,52,87]$ and anti-oxLDL autoantibody (AuAb-oxLDL) $[50,51,87]$ in the blood. The lipid peroxidation markers were found significantly higher in the patients with severe or active psoriasis (PASI $>3$ ) than in the patients with mild or inactive psoriasis $($ PASI $<3)$ [43]. The accumulation of ox-LDL was detected in the upper epidermis of the involved skin from psoriatic patients by direct immune-fluorescent method [18]. OxLDLs are able to initiate inflammation and to influence the adhesion of endothelial cells and on oxidant status of the blood vessels cells, which is important in the development of early atherogenesis [53]. They are also antigenic and can elicit an immune response with a generation of circulating antibodies AuAb-oxLDL and $\beta 2$-GP1-dependent anticardiolipin antibodies $(\mathrm{aCL})$, as a consequence of structural similarity between ox-LDL surface structure and $\beta 2$-GP1-anionic phospholipid complex, the antigenic target for aCL [91].
The level of AuAb-oxLDL has been suggested to reflect the in vivo oxidation of LDL. The importance of AuAb-oxLDL in diseases such as myocardial infarct, atherosclerosis, diabetes mellitus, renal failure, systemic lupus erythematosus (SLE), rheumatoid arthritis (RA), Behset's disease, and psoriasis was suggested [51]. aCL level is increased in psoriatic patients. It could be a useful marker in predicting atherosclerosis risk, because it may promote atherosclerotic lesions [91]. In plasma and red blood cells (RBCs) of psoriatic patients, increased levels of MDA were observed which indicates an advanced peroxidative process in erythrocyte membranes. The increased peroxidation of lipid bilayer caused by a decrease of antioxidant enzyme activities may be the essential mechanism of the membrane fluidity decrease observed in association with the exacerbation of the disease $[88,89,92]$. The impaired antioxidant status is shown by decreased serum levels of erythrocyte SOD [51,90] and GSH-Px activities [51, 90, 92, 93] of increased PON1 activity [54] and of increased [90] or decreased [51] serum CAT activity in patients with psoriasis. Nonenzymatic antioxidants were also decreased $[51,92,93]$. Changes in the elastase neutrophil ratio illustrating an increase in neutrophil function can be a marker of psoriasis [43]. In general, total antioxidant status (TAS) in psoriasis is reduced $[43,51]$, or there are no significant differences between patients and healthy controls $[52,54,89]$.

A high serum total homocysteine (tHcy) level was observed in patients with psoriasis. The main mechanisms of hyperhomocysteinemia engaged in the development of atherothrombosis are endothelial injury, platelet activation, oxidative modification of low-density lipoproteins, and endothelial-leukocyte interactions $[94,95]$. There was 
a positive relationship between an increased level of AuAboxLDL and plasma tHcy levels which may play an important role in development of atherothrombotic complications in psoriatic patients [96].

Oxidative stress may have a pivotal role in both therapeutic mechanisms and side effects induced by anthralin. Systemic antioxidant administration may provide an opportunity for therapeutic intervention against anthralin-associated toxicities [88]. Lipid peroxidation is the earliest response mediating activation of downstream signalling events in peripheral blood mononuclear cells (PBMCs) and keratinocytes by anthralin. It leads to the activation of c-jun$\mathrm{N}$-terminal kinase (JNK), event relevant for the regulation of cellular proliferation and apoptosis [97].

It is well known that phototherapy is recommended in the psoriasis treatment. However, both ultraviolet $A$ and $B$ radiation (UVA and UVB) apart from therapeutic and immunomodulating action induce production of ROS and increase lipid peroxidation [53]. There was a difference between the effect of phototherapy on lipid parameters in patients with mild or moderate psoriasis (PASI1 from 5.4 to 22.1; mean 15.2 \pm 4.9 ) and severe psoriasis (PASI 2, PASI 22.5 to 49.2 ; mean $30.3 \pm 5.8)$. Exacerbated skin manifestations of psoriasis are accompanied by an increase of dyslipidaemia and oxidation processes. Therefore patients with severe psoriasis are exposed to higher risk of atherosclerosis. PASI2 patients have higher level of AuAb-oxLDL than PASI1 patients. Phototherapy increased TC, LDL, and AuAb-oxLDL level in PASI1 patients. Level of ox-LDL was decreased after phototherapy in patients with severe psoriasis and it was accompanied by increase of ferric reducing ability of plasma (FRAP) and negative correlation with AuAboxLDL level. It can be explained by therapeutic action of phototherapy and reduction of inflammatory processes [53].

\section{Peroxisome Proliferator-Activated Receptors (PPARs) and Liver X Receptors (LXRs)}

The epidermis is a very active site of lipid metabolism, and all peroxisome proliferator-activated receptor (PPAR) and liver $\mathrm{X}$ receptor (LXR) isoforms are expressed in the epidermis. An increased expression of PPAR $\beta / \delta$ and a decreased expression of PPAR $\alpha$ and PPAR $\gamma$ were observed in the lesional skin of patients with psoriasis and atopic dermatitis [98-100]. Since the prevalence of metabolic syndrome is increased in psoriasis [101], a combination of insulin resistance, obesity, or chronic inflammation may trigger the expression of $\operatorname{PPAR} \beta / \delta$, which in turn contributes to a nonterminated regenerative skin phenotype. This disease mechanism would be expected to be aggravated by acute inflammation, or stress via the induction of PPAR $\beta / \delta$ by TNF $\alpha$ and stress-activated kinase [102].

PPARs $\alpha, \beta / \delta, \gamma$, and LXRs $\alpha$ and $\beta$ belong to the nuclear steroid hormone receptor superfamily, which are regulated by fatty acid derivatives capable of controlling lipid and lipoprotein metabolism, cell proliferation, differentiation, and apoptosis of various cell types, including keratinocytes and sebaceous gland cells. These receptors play also a role in cutaneous carcinogenesis [100].

An activation of PPARs and LXRs leads to stimulation of epidermal lipid synthesis, formation and secretion of lamellar bodies, and activation of enzymes required for the extracellular processing of lipids in the stratum corneum, resulting in the formation of lamellar membranes that mediate permeability barrier function. PPAR $\gamma$ activation appeared to have the least effect on epidermal lipid synthesis among the PPAR and LXR activators tested. PPAR $\beta / \delta$ is the key PPAR isoform involved in lamellar body formation and secretion as well as in lipid storage $[103,104]$.

PPAR- $\alpha$ can also modulate the inflammatory response by inhibiting cytokine secretion, maturation, and migration and the T-cell-stimulatory activity of the epidermal antigenpresenting cell, the Langerhans cell. This was associated with decreased levels of phosphorylated nuclear factor- $\kappa \mathrm{B}$ (NF$\kappa \mathrm{B})$ [105]. Moreover, PPAR- $\alpha$ activation induces antioxidant enzymes, such as catalase or SOD, which would reduce the oxidative stress and the activation of mediators of inflammatory response [88]. The anti-inflammatory role of $\operatorname{PPAR} \beta / \delta$ and PPAR $\gamma$ in the skin is uncertain, but it is suggested that they downregulate inflammation. LXR activators have a potent anti-inflammatory activity in both the irritant and allergic contact models of cutaneous inflammation $[106,107]$. These findings suggest the possibility of PPAR- $\alpha$ activators as novel nonsteroidal anti-inflammatory drugs in the topical treatment of common inflammatory diseases such as atopic dermatitis, psoriasis, acne, and photodermatitis. A great improvement of skin lesions and also of psoriatic arthritis had been initially documented in patients with psoriasis treated with the oral PPAR $\gamma$ activators troglitazone $[108,109]$ or pioglitazone [110-112]. In contrast, topical treatment of psoriatic skin with the PPAR activators tetradecylthioacetic acid and rosiglitazone did not show a significant effect $[113,114]$.

LXR and PPAR influence also the synthesis of cholesterol sulfate, which is a potent regulator of epidermal differentiation and corneocyte desquamation. The stimulation of both the cellular and extracellular components of the stratum corneum by $\operatorname{PPAR} \alpha$ and LXR activators results in the generation of a mature, functionally competent stratum corneum earlier in fetal development. Moreover, in a mouse model of epidermal hyperproliferation induced by repeated barrier disruption to the flank skin of hairless mice [115], topical PPAR $\alpha$ activation inhibited proliferation and increased keratinocyte apoptosis. The activation of PPAR $\alpha$ in the epidermis decreases keratinocyte proliferation. The absence of $\operatorname{PPAR} \beta / \delta$ leads to increased keratinocyte proliferation and under some experimental conditions $\operatorname{PPAR} \beta / \delta$ activators inhibit keratinocyte proliferation. It has been demonstrated that activation of $\operatorname{PPAR} \beta / \delta$ induces endothelial cell proliferation and angiogenesis [116]. It was suggested that in the hyperproliferative epidermis of psoriatic skin, $\operatorname{PPAR} \beta / \delta$ overexpression mediates keratinocyte proliferation via $\mathrm{NF}-\kappa \mathrm{B}$ [98]. The proliferative state of the keratinocytes may determine the effect of PPAR $\gamma$ activation on keratinocyte proliferation. A proapoptotic effect of PPAR $\gamma$ in $\mathrm{T}$ cells has been observed [117], and activation of 

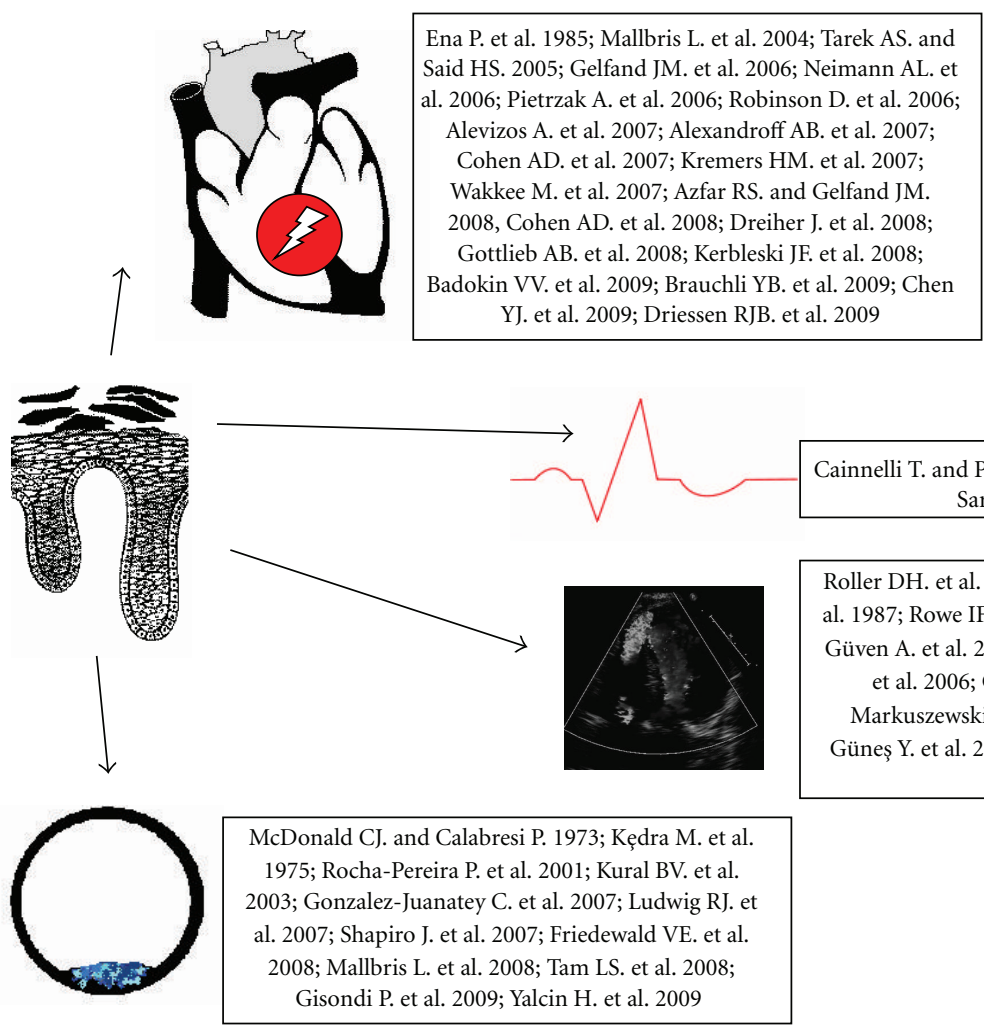

Cainnelli T. and Petruzellis V. 1964; Roller. et al. 1979; Saricaoglu H. et al. 2003

Roller DH. et al. 1979; Pines A. et al. 1986; Moya JL. et al. 1987; Rowe IF. et al. 1991; Wojas-Pelc A. et al. 2002; Güven A. et al. 2003; Saricaoglu H. et al. 2003; Biyik I. et al. 2006; Gonzalez-Juanatey C. et al. 2006; Markuszewski L. et al. 2006; Güneş Y. et al. 2007; Güneş Y. et al. 2008; Blendea D. et al. 2009; Savoir, F., 2010

Figure 4: Psoriasis and cardiovascular abnormalities. This figure is a modified one (after permission) from [19].

$\operatorname{PPAR} \gamma$ has an inhibitory effect on psoriasis, whereas this is not the case with $\operatorname{PPAR} \beta / \delta$ activation $[118,119]$. In LXRs deficient mice, thinning of the epidermis was observed [120].

\section{Cardiovascular Disease (CVD)}

In patients with psoriasis one observes an increased risk of cardiovascular disease which can be explained by several possible biological factors [6, 121-125]. Psoriasis is associated with traditional risk factors of CVD such as increased BMI, hyperlipidemia, hypertension, type 2 diabetes mellitus, and cigarette smoking [124-126]. Obesity has been shown to be an independent risk factor for the development of psoriasis and is also associated with more severe psoriasis and cardiovascular complications [125]. The persistent skin inflammation may contribute to a dyslipidemia and premature atherosclerosis [126, 127]. The duration of disease and its severity are related to the incidence of cardiovascular diseases, such as myocardial infarction, coronary artery disease and stroke $[16,38-40,43-47,54,101,121,122,127-$ 135]. In psoriatic patients, lipid abnormalities are correlated with increased mortality due to myocardial infarction and stroke $[129,134]$. Elevated level of C-reactive protein (CRP) is a risk factor for CVD and it can predict long-term risk for cardiovascular events [136]. The treatment for psoriasis such as retinoids and cyclosporine may be also responsible for initiation of hyperlipidemia which can promote future CVD [137-141]. Methotrexate use is associated with hyperhomocysteinemia, also a risk factor for cardiovascular disease [142].

There was a strong association observed between arterial stiffness, which is endothelial dysfunction marker, and the risk of cardiovascular events. Pulse wave velocity (PWV) is the gold standard measurement of arterial stiffness and in the patients with psoriasis and psoriatic arthritis an increased femoral-carotid PWV was observed [127, 143]. There were also functional and structural changes in the myocardium, changes in electrocardiographic activity, such as increased $\mathrm{P}$ wave dispersion, and structural changes in coronary vessels in psoriatic patients (Figure 4) [7, 19, 144].

\section{NTproBNP}

In recent years, the probable usefulness of NTproBNP as a biomarker of heart failure (HF) has been established. There was a positive correlation observed between NT-pro BNP in blood serum of psoriatic patients and heart diseases as well as acceptation of the disease [145].

\section{Lipid and Immunologic Abnormalities}

In psoriasis, the association between lipid and immunologic abnormalities was observed, that is why the disease could be described as an immunometabolic syndrome $[128,146]$. Psoriasis is a chronic inflammation characterized by increased Th-1 and Th-17 $\mathrm{T}$ cell activity [128]. The significant role of cytokines, such as TNF- $\alpha$, IL- 6 , 
IL-8, IFN-gamma, IL-1, and IL-17 in the generation of proatheromatous abnormalities (dyslipidemia, insulin resistance, endothelial dysfunction, clotting system activation, and pro-oxidative stress) was reported $[127,128,146$, 147]. TNF- $\alpha$ is a potent activator of c-Jun amino-terminal kinase, which stimulates the main regulator of proinflammatory activity protein-1 and is connected with obesity [128]. TNF- $\alpha$ can also lead to insulin resistance by inhibiting phosphorylation of insulin receptor tyrosine and of insulin receptor substrate 1 . Treatment with TNF- $\alpha$ inhibitors affects the increase of HDL level [128]; in particular, TNF may affect endothelium dysfunction by decreasing the levels of nitric oxide synthase and cyclooxygenase 1 [127].

\section{Effects of Antipsoriatics and Hypolipemic Drugs on Psoriasis}

Antipsoriatic drugs can be also responsible for the lipid profile disturbances in psoriatic patients, because of their action on the circulating lipids [148-156]. Retinoids have the most potent activity on increasing the levels of triglycerides, total cholesterol, LDL cholesterol, and VLDL cholesterol and simultaneously decreasing the HDL fraction [137-140]. There are some reports that the diet enriched with fish oil can reduce side effects of these drugs $[157,158]$. Cyclosporin has milder effects on the lipid profile, but it can also lead to some abnormalities for example TG elevation [159]. TNF- $\alpha$ inhibitors can cause an increase of serum triglyceride levels, but they have beneficial effects on the increase of HDL level and are able to decrease blood insulin levels [141, 160-162].

Hyperlipidemia is treated with statins which effectively reduce CRP and TNF- $\alpha$ levels as well as decrease levels of low-density lipoproteins and alleviate the arterial stiffness. Statins also downregulate adhesion molecules such as LFA1 and ICAM-1 on leukocytes and endothelial cells which are essential in leukocyte activation, leukocyte migration to inflammatory sites, and immunologic cytotoxicity [163]. Statins have the inhibiting action on the expression of MHC II molecules, chemokine receptors on Th-1 cell and the production of NO [163]. These drugs are generally beneficial for psoriatic patients and reduce the risk of cardiovascular diseases. However, there was also a case of exacerbation of psoriasis after the treatment with three different statins and bezafibrate [164]. Fibrates, used to decrease cholesterol levels, may also affect rapid and acute development of clinical symptoms of psoriasis.

\section{Summary}

The lipid disturbances are recognised as a very important part in the pathogenesis of psoriasis. The results of the majority of the studies are coherent and indicate that the increased total cholesterol, LDL cholesterol and/or triglycerides, and decreased HDL cholesterol in psoriatic patients' serum the composition of apolipoproteins, and increased production of oxygen metabolites are features of the metabolic syndrome. These factors have also a great impact on some comorbidities observed in psoriatic patients especially on cardiovascular diseases. These lipid disturbances are also connected with immunological abnormalities, that is why psoriasis could be classified as an immunometabolic disease. In spite of the intensive investigations, the explanation of the steps of disease mechanisms in psoriasis have not been recognised so far. On the basis the literature data, further studies should be designed to connect the lipid and immunological disturbances.

The review of the last years suggests an introduction of some new therapeutic methods for psoriatic patients as for example statins. Their immunomodulatory activities like influence on $\mathrm{T}$ cells and antigen presenting cells function, influence on leukocyte adhesion and endothelial cell function are discussed. In many papers the importance of reduction of animal fat, introduction of fish and plant oil, preparations with the omega- 6 and omega- 3 fatty acids as well as BMI reduction, prevention of obesity and quitting addictions were suggested.

\section{References}

[1] M. Icen, C. S. Crowson, M. T. McEvoy, F. J. Dann, S. E. Gabriel, and H. M. Kremers, "Trends in incidence of adultonset psoriasis over three decades: a population-based study," Journal of the American Academy of Dermatology, vol. 60, no. 3, pp. 394-401, 2009.

[2] F. C. Wilson, M. Icen, C. S. Crowson, M. T. McEvoy, S. E. Gabriel, and H. M. Kremers, "Incidence and clinical predictors of psoriatic arthritis in patients with psoriasis: a population-based study," Arthritis Care and Research, vol. 61, no. 2, pp. 233-239, 2009.

[3] V. Chandran and S. P. Raychaudhuri, "Geoepidemiology and environmental factors of psoriasis and psoriatic arthritis," Journal of Autoimmunity, vol. 34, no. 3, pp. J314-J321, 2010.

[4] M. Romanowska, N. Al Yacoub, H. Seidel et al., "PPAR $\delta$ enhances keratinocyte proliferation in psoriasis and induces heparin-binding EGF-like growth factor," Journal of Investigative Dermatology, vol. 128, no. 1, pp. 110-124, 2008.

[5] Y.-J. Chen, J.-L. Shen, C.-Y. Wu, Y.-T. Chang, C.-M. Chen, and F.-Y. Lee, "Elevated plasma osteopontin level is associated with occurrence of psoriasis and is an unfavorable cardiovascular risk factor in patients with psoriasis," Journal of the American Academy of Dermatology, vol. 60, no. 2, pp. 225-230, 2009.

[6] T. Nijsten and M. Wakkee, "Complexity of the association between psoriasis and comorbidities," Journal of Investigative Dermatology, vol. 129, no. 7, pp. 1601-1603, 2009.

[7] A. Pietrzak, K. Janowski, J. Łopatynski et al., "Psoriasis and heart. Something new under the sun," Giornale Italiano di Dermatologia e Venereologia, vol. 141, no. 5, pp. 457-463, 2006.

[8] A. Pietrzak, B. Lecewicz-Toruń, and G. Kạdziela-Wypyska, "Changes in the digestive system in patients suffering from psoriasis," Annales Universitatis Mariae Curie-Sklodowska. Sectio D, vol. 53, pp. 187-194, 1998.

[9] M. Chibowska, "Role of serum lipids in pseriasis," Przeglad Dermatologiczny, vol. 57, no. 2, pp. 255-260, 1970.

[10] A. Pietrzak, B. Toruniowa, B. Pietrzak, and J. Chwaluk, "Lipid profile in psoriatic patients according to sex and age," Przeglad Dermatologiczny, vol. 81, no. 5, pp. 441-449, 1994.

[11] A. Pietrzak, I. Jastrzebska, D. Krasowska et al., "Serum pancreatic lipase [EC 3.1.1.3] activity, serum lipid profile and 
peripheral blood dendritic cell populations in normolipidemic males with psoriasis," Journal of Molecular Catalysis B, vol. 40, no. 3-4, pp. 144-154, 2006.

[12] D. I. Wilkinson, "Lipid metabolism in psoriasis," in Proceedings of the International Symposium on Psoriasis, E. M. Farber, A. J. Cox, and P. H. Jacobs, Eds., pp. 277-287, Stanford University Press, Stanford, Calif, USA, 1971.

[13] M. Yamaoka-Tojo, T. Tojo, R. Kosugi, et al., "Effects of ezetimibe add-on therapy for high-risk patients with dyslipidemia," Lipids in Health and Disease, vol. 8, p. 41, 2009.

[14] R. Zawydiwski, D. L. Sprecher, M. J. Evelegh, P. Horsewood, C. Carte, and M. Patterson, "A novel test for the measurement of skin cholesterol," Clinical Chemistry, vol. 47, no. 7, pp. 1302-1304, 2001.

[15] J. H. Stein, W. S. Tzou, J. M. DeCara et al., "Usefulness of increased skin cholesterol to identify individuals at increased cardiovascular risk (from the predictor of advanced subclinical atherosclerosis study)," American Journal of Cardiology, vol. 101, no. 7, pp. 986-991, 2008.

[16] L. Mallbris, F. Granath, A. Hamsten, and M. Ståhle, "Psoriasis is associated with lipid abnormalities at the onset of skin disease," Journal of the American Academy of Dermatology, vol. 54, no. 4, pp. 614-621, 2006.

[17] H. Ishikawa and H. Sato, "Demonstration of betalipoproteins in the psoriatic skin by immunofluorescent technique," Archiv für Dermatologische Forschung, vol. 30, no. 8, pp. 191-206, 1974.

[18] N. S. Tekin, I. O. Tekin, F. Barut, and E. Y. Sipahi, "Accumulation of oxidized low-density lipoprotein in psoriatic skin and changes of plasma lipid levels in psoriatic patients," Mediators of Inflammation, vol. 2007, Article ID 78454, 5 pages, 2007.

[19] A. Pietrzak, G. Chodorowska, J. Szepietowski, A. ZalewskaJanowska, D. Krasowska, and J. Hercogová, "Psoriasis and serum lipid abnormalities," Dermatologic Therapy, vol. 23, no. 2, pp. 160-173, 2010.

[20] J. M. Jungersted, L. I. Hellgren, G. B. E. Jemec, and T. Agner, "Lipids and skin barrier function-a clinical perspective," Contact Dermatitis, vol. 58, no. 5, pp. 255-262, 2008.

[21] O. Bleck, D. Abeck, J. Ring et al., "Two ceramide subfractions detectable in Cer(AS) position by HPTLC in skin surface lipids of non-lesional skin of atopic eczema," Journal of Investigative Dermatology, vol. 113, no. 6, pp. 894-900, 1999.

[22] L. Landmann, "Epidermal permeability barrier: transformation of lamellar granule-disks into intercellular sheets by a membrane-fusion process, a freeze-fracture study," Journal of Investigative Dermatology, vol. 87, no. 2, pp. 202-209, 1986.

[23] P. M. Elias and G. K. Menon, "Structural and lipid biochemical correlates of the epidermal permeability barrier," Advances in Lipid Research, vol. 24, pp. 1-26, 1991.

[24] S. Grayson and P. M. Elias, "Isolation and lipid biochemical characterization of stratum corneum membrane complexes: implications for the cutaneous permeability barrier," Journal of Investigative Dermatology, vol. 78, no. 2, pp. 128-135, 1982.

[25] M. Q. M. Man, K. R. Feingold, C. R. Thornfeldt, and P. M. Elias, "Optimization of physiological lipid mixtures for barrier repair," Journal of Investigative Dermatology, vol. 106, no. 5, pp. 1096-1101, 1996.

[26] W. M. Holleran, K. R. Feingold, M. Q. M. Man, W. N. Gao, J. M. Lee, and P. M. Elias, "Regulation of epidermal sphingolipid synthesis by permeability barrier function," Journal of Lipid Research, vol. 32, no. 7, pp. 1151-1158, 1991.

[27] S. Motta, M. Monti, S. Sesana, L. Mellesi, R. Ghidoni, and R. Caputo, "Abnormality of water barrier function in psoriasis: role of ceramide fractions," Archives of Dermatology, vol. 130, no. 4, pp. 452-456, 1994.

[28] R. Ghadially, J. T. Reed, and P. M. Elias, "Stratum corneum structure and function correlates with phenotype in psoriasis," Journal of Investigative Dermatology, vol. 107, no. 4, pp. 558-564, 1996.

[29] B. S. Khyshiktuev and E. V. Falko, "Alterations in the parameters of lipid metabolism in different biological objects in psoriatic patients during exacerbation and remission," Vestnik Dermatologii i Venerologii, vol. 6, pp. 40-43, 2005.

[30] V. Ansidei, M. Binazzi, A. Cantelmi, A. Gaiti, and G. Porcellati, "Phospholipid involvement in psoriatic epidermis," Italian Journal of Biochemistry, vol. 30, no. 1, pp. 40-45, 1981.

[31] E. S. Fortinskaia, T. I. Torkhovskaia, G. I. Sharapova, T. K. Loginova, Z. I. Kliuchnikova, and E. M. Khalilov, "Features of distribution of free and esterified cholesterol in the epidermis, biological membranes and plasma lipoproteins in psoriasis," Klinicheskaia Laboratornaia Diagnostika, no. 4, pp. 38-43, 1996.

[32] B. S. Khyshiktuyev, T. M. Karavayeva, and Ye. V. Falko, "Variability of quantitative changes in short-chain fatty acids in the serum and epidermis in psoriasis," Klinichescheskaya Laboratornaya Diagnostika, no. 8, pp. 22-24, 2008.

[33] F. R. Maxfield and I. Tabas, "Role of cholesterol and lipid organization in disease," Nature, vol. 438, no. 7068, pp. 612$621,2005$.

[34] C. E. Orfanos, "Scanning electron microscopy in psoriasis," in Proceedings of the International Symposium on Psoriasis, E. M. Farber, A. J. Cox, and P. H. Jacobs, Eds., pp. 169-185, Stanford University Press, Stanford, Calif, USA, 1971.

[35] D. Tsambaos, A. Kalofoutis, and J. Stratigos, “Thin-layer chromatography of phospholipid components of normal and psoriatic epidermis," British Journal of Dermatology, vol. 97, no. 2, pp. 135-138, 1977.

[36] M. Wakkee, Psoriasis: comorbidity and treatment, Doctoral thesis, Erasmus University Rotterdam, Rotterdam, The Netherlands, 2010.

[37] M. Ponec, L. Havekes, J. Kempenaar, and B. J. Vermeer, "Cultured human skin fibroblasts and keratinocytes: differences in the regulation of cholesterol synthesis," Journal of Investigative Dermatology, vol. 81, no. 2, pp. 125-130, 1983.

[38] M. Farshchian, A. Zamanian, M. Farshchian, A.-R. Monsef, and H. Mahjub, "Serum lipid level in Iranian patients with psoriasis," Journal of the European Academy of Dermatology and Venereology, vol. 21, no. 6, pp. 802-805, 2007.

[39] P. Gisondi, G. Tessari, A. Conti et al., "Prevalence of metabolic syndrome in patients with psoriasis: a hospitalbased case-control study," British Journal of Dermatology, vol. 157, no. 1, pp. 68-73, 2007.

[40] A. D. Cohen, M. Sherf, L. Vidavsky, D. A. Vardy, J. Shapiro, and J. Meyerovitch, "Association between psoriasis and the metabolic syndrome: a cross-sectional study," Dermatology, vol. 216, no. 2, pp. 152-155, 2008.

[41] L.-S. Tam, B. Tomlinson, T. T.-W. Chu et al., "Cardiovascular risk profile of patients with psoriatic arthritis compared to controls-the role of inflammation," Rheumatology, vol. 47, no. 5, pp. 718-723, 2008.

[42] G. Ferretti, O. Simonetti, A. M. Offidani et al., "Changes of plasma lipids and erythrocyte membrane fluidity in psoriatic children," Pediatric Research, vol. 33, no. 5 I, pp. 506-509, 1993.

[43] P. Rocha-Pereira, A. Santos-Silva, I. Rebelo, A. Figueiredo, A. Quintanilha, and F. Teixeira, "Dislipidemia and oxidative 
stress in mild and in severe psoriasis as a risk for cardiovascular disease," Clinica Chimica Acta, vol. 303, no. 1-2, pp. 33-39, 2001.

[44] M. Akhyani, A. H. Ehsani, R. M. Robati, and A. M. Robati, "The lipid profile in psoriasis: a controlled study," Journal of the European Academy of Dermatology and Venereology, vol. 21, no. 10, pp. 1330-1332, 2007.

[45] Z. Javidi, N. T. Meibodi, and Y. Nahidi, "Serum lipids abnormalities and psoriasis," Indian Journal of Dermatology, vol. 52, no. 2, pp. 89-92, 2007.

[46] T. Amin, E. Saied, and S. H. Abdou, "Atherosclerotic risk in psoriasis," Journal of Pan-Arab League of Dermatologists, vol. 16, no. 2, pp. 39-45, 2005.

[47] D. R. Bajaj, S. M. Mahesar, B. R. Devrajani, and M. P. Iqbal, "Lipid profile in patients with psoriasis presenting at Liaquat University Hospital Hyderabad," Journal of the Pakistan Medical Association, vol. 59, no. 8, pp. 512-515, 2009.

[48] C. Reynoso-von Drateln, E. Martínez-Abundis, B. R. Balcázar-Muñoz, R. Bustos-Saldaña, and M. González-Ortiz, "Lipid profile, insulin secretion, and insulin sensitivity in psoriasis," Journal of the American Academy of Dermatology, vol. 48, no. 6, pp. 882-885, 2003.

[49] S. Piskin, F. Gurkok, G. Ekuklu, and M. Senol, "Serum lipid levels in psoriasis," Yonsei Medical Journal, vol. 44, no. 1, pp. 24-26, 2003.

[50] A. Örem, G. Çimşit, O. Değer, C. Örem, and B. Vanizor, “The significance of autoantibodies against oxidatively modified low-density lipoprotein (LDL) in patients with psoriasis," Clinica Chimica Acta, vol. 284, no. 1, pp. 81-88, 1999.

[51] B. Vanizor Kural, A. Örem, G. U. Çimşit, Y. E. Yandi, and M. Calapoğlu, "Evaluation of the atherogenic tendency of lipids and lipoprotein content and their relationships with oxidant-antioxidant system in patients with psoriasis," Clinica Chimica Acta, vol. 328, no. 1-2, pp. 71-82, 2003.

[52] S. Coimbra, H. Oliveira, F. Reis et al., "Circulating levels of adiponectin, oxidized LDL and C-reactive protein in Portuguese patients with psoriasis vulgaris, according to body mass index, severity and duration of the disease," Journal of Dermatological Science, vol. 55, no. 3, pp. 202-204, 2009.

[53] E. Hadas, A. Bożek, and J. Jarząb, "Impact of phototherapy on selected lipid profile indices in psoriatic patients allowing for intensification of the disease," Postẹpy Dermatologii $i$ Alergologii, vol. 24, no. 5, pp. 215-223, 2007.

[54] A. Toker, M. Kadi, A. K. Yildirim, H. Aksoy, and F. Akçay, "Serum lipid profile paraoxonase and arylesterase activities in psoriasis," Cell Biochemistry and Function, vol. 27, no. 3, pp. 176-180, 2009.

[55] M. Kuliszkiewicz-Janus, A. S. Mohamed, and N. Abod, "The biology of HDL lipoprotein and its antisclerotic activity," Postepy Higieny i Medycyny Doświadczalnej, vol. 60, pp. 307315, 2006.

[56] T. F. Daniels, K. M. Killinger, J. J. Michal, R. W. Wright Jr., and Z. Jiang, "Lipoproteins, cholesterol homeostasis and cardiac health," International Journal of Biological Sciences, vol. 5, no. 5, pp. 474-488, 2009.

[57] G. B. Niestierienko, G. H. Kogon, and F. D. Ulanowska, "Lipidnyj obmien u bolnych sizmienieniami kostnosustawnowo apparata pri psoriaticzieskoj boliezni," Vestnik Dermatologii i Venerologii, vol. 6, p. 31, 1971.

[58] B. T. Wilienczik, "Frakcji fosfolipidow syworotki krowi bolnych psoriazom i egziemoj," Vestnik Dermatologii i Venerologii, vol. 6, p. 71, 1971.
[59] T. S. Panfilova and G. V. Tananova, "Lipid metabolic indices of children with psoriasis," Vestnik Dermatologii i Venerologii, no. 6, pp. 60-61, 1983.

[60] C. Vahlquist, B. Berne, and M. Boberg, "The fatty-acid spectrum in plasma and adipose tissue in patients with psoriasis," Archives of Dermatological Research, vol. 278, no. 2, pp. 114-119, 1985.

[61] I. P. Iwanowa and T. E. Mariejewa, "Naruszienija pierieisnowo okislienija lipidow aktiwnosti lizosomalnych gidrolaz i ich korriekcja u bolnych psoriazom," Vestnik Dermatologii i Venerologii, vol. 4, p. 26, 1987.

[62] M. Chibowska, Biochemical studies of serum lipids and histochemical studies on lipids of the soft palate mucosa in palatal lipidophilia and psoriasis with associated prelipidophilia, Doctoral thesis, Klinika Dermatologii Akademii Medycznej w Lublinie, Lublin, Poland, 1967.

[63] S. I. Dowzanski, W. N. Szierstniewa, and I. G. Graszkina, "Sierdieczno sosudiataja sistiema i lipidnyjobmien u bolnych psoriazom," Vestnik Dermatologii i Venerologii, vol. 17, 1982.

[64] G. Mingrone, A. V. Greco, A. Venier, E. Peruzzi, and F. Serri, "Lipid synthesis from the liver in patients with psoriasis," Archives of Dermatological Research, vol. 268, no. 3, pp. 271$276,1980$.

[65] S. Brenner, A. Krakowski, O. Levtov, D. Heldenberg, B. Werbin, and I. Tamir, "Serum lipids in patients with psoriasis," Dermatologica, vol. 150, p. 196, 1975.

[66] E. Campalani, M. H. Allen, D. Fairhurst et al., "Apolipoprotein E gene polymorphisms are associated with psoriasis but do not determine disease response to acitretin," British Journal of Dermatology, vol. 154, no. 2, pp. 345-352, 2006.

[67] A. Karpouzis, R. Caridha, G. Tripsianis, C. Michailidis, G. Martinis, and S. V. Veletza, "Apolipoprotein e gene polymorphism in psoriasis," Archives of Dermatological Research, vol. 301, no. 6, pp. 405-410, 2009.

[68] H. Miyauchi, "Immunohistochemical study for the localization of apolipoprotein AI, B100, and E in normal and psoriatic skin," Igaku Kenkyu. Acta Medica, vol. 61, no. 2, pp. 79-86, 1991.

[69] P. G. Frank and Y. L. Marcel, "Apolipoprotein A-I: structurefunction relationships," Journal of Lipid Research, vol. 41, no. 6, pp. 853-872, 2000.

[70] R. Barbaras, P. Puchois, J.-C. Fruchart, and G. Ailhaud, "Cholesterol efflux from cultured adipose cells is mediated by LpAI particles but not by LpAI:AII particles," Biochemical and Biophysical Research Communications, vol. 142, no. 1, pp. 63-69, 1987.

[71] P. J. Blanche, E. L. Gong, T. M. Forte, and A. V. Nichols, "Characterization of human high-density lipoproteins by gradient gel electrophoresis," Biochimica et Biophysica Acta, vol. 665, no. 3, pp. 408-419, 1981.

[72] W. V. Brown and M. L. Baginsky, "Inhibition of lipoprotein lipase by an apoprotein of human very low density lipoprotein," Biochemical and Biophysical Research Communications, vol. 46, no. 2, pp. 375-382, 1972.

[73] R. M. Krauss, P. N. Herbert, R. I. Levy, and D. S. Fredrickson, "Further observations on the activation and inhibition of lipoprotein lipase by apolipoproteins," Circulation Research, vol. 33, no. 4, pp. 403-411, 1973.

[74] P. K. J. Kinnunen and C. Ehnholm, "Effect of serum and C apoproteins from very low density lipoproteins on human postheparin plasma hepatic lipase," FEBS Letters, vol. 65, no. 3, pp. 354-357, 1976.

[75] E. Windler and R. J. Havel, "Inhibitory effects of C apolipoproteins from rats and humans on the uptake of 
triglyceride-rich lipoproteins and their remnants by the perfused rat liver," Journal of Lipid Research, vol. 26, no. 5, pp. 556-565, 1985.

[76] A. Pietrzak, J. Kạdzielewski, K. Janowski et al., "Lipoprotein (a) in patients with psoriasis: associations with lipid profiles and disease severity," International Journal of Dermatology, vol. 48, no. 4, pp. 379-387, 2009.

[77] T. Xiao, C. Yang, Y. Xiao, and F. Song, "Serum apolipoprotein levels of psoriatic patients with normal serum lipid levels," Chinese Medical Sciences Journal, vol. 12, no. 4, pp. 224-228, 1997.

[78] M. Seishima, M. Seishima, S. Mori, and A. Noma, "Serum lipid and apolipoprotein levels in patients with psoriasis," British Journal of Dermatology, vol. 130, no. 6, pp. 738-742, 1994.

[79] A. Barba, D. Schena, S. Ferrari, and L. Grigolini, "Observations on lipid metabolism in patients affected with psoriasis. Preliminary findings," Giornale Italiano di Dermatologia $e$ Venereologia, vol. 122, no. 3, pp. 85-89, 1987.

[80] T. P. Leren, K. Maartmann-Moe, P. Thune, and K. Berg, "Low density lipoprotein receptors in cultured skin fibroblasts from psoriasis patients," Clinical Genetics, vol. 25, no. 3, pp. 230-241, 1984.

[81] F. Oliveiro, P. Sfriso, G. Baldo et al., "Apolipoprotein A-I and cholesterol in synovial fluid of patients with rheumatoid arthritis, psoriatic arthritis and osteoarthritis," Clinical and Experimental Rheumatology, vol. 27, no. 1, pp. 79-83, 2009.

[82] R. W. Mahley, "Apolipoprotein E: cholesterol transport protein with expanding role in cell biology," Science, vol. 240, no. 4852, pp. 622-630, 1988.

[83] R. W. Mahley and S. C. Rall Jr., "Apolipoprotein E: far more than a lipid transport protein," Annual Review of Genomics and Human Genetics, vol. 1, no. 2000, pp. 507-537, 2000.

[84] H. Furumoto, K. Nakamura, T. Imamura et al., "Association of apolipoprotein allele $\varepsilon 2$ with psoriasis vulgaris in Japanese population," Archives of Dermatological Research, vol. 289, no. 9, pp. 497-500, 1997.

[85] P. Coto-Segura, E. Coto, V. Alvarez, and J. Santos-Juanes, "Apolipoprotein $\varepsilon 4$ allele is associated with psoriasis severity: reply," Archives of Dermatological Research, vol. 302, no. 3, pp. 237-238, 2010.

[86] A. A. Geronikaki and A. M. Gavalas, "Antioxidants and inflammatory disease: synthetic and natural antioxidants with anti-inflammatory activity," Combinatorial Chemistry and High Throughput Screening, vol. 9, no. 6, pp. 425-442, 2006.

[87] R. Rashmi, K. S. J. Rao, and K. H. Basavaraj, "A comprehensive review of biomarkers in psoriasis," Clinical and Experimental Dermatology, vol. 34, no. 6, pp. 658-663, 2009.

[88] S. Briganti and M. Picardo, "Antioxidant activity, lipid peroxidation and skin diseases. What's new," Journal of the European Academy of Dermatology and Venereology, vol. 17, no. 6, pp. 663-669, 2003.

[89] S. Nassiri, F. Malekzad, M. Sarlak, et al., "Interplay among antioxidants and oxidants in psoriasis," Iranian Journal of Dermatology, vol. 12, pp. 56-59, 2009.

[90] M. Yildirim, H. S. Inaloz, V. Baysal, and N. Delibas, "The role of oxidants and antioxidants in psoriasis," Journal of the European Academy of Dermatology and Venereology, vol. 17, no. 1, pp. 34-36, 2003.

[91] A. Campanati, O. Simonetti, B. Silvestri et al., "Anticardiolipin antibodies expression in psoriasis," Giornale Italiano di Dermatologia e Venereologia, vol. 139, no. 3, pp. 165-170, 2004.
[92] I. Kökçam and M. Nazıroğlu, "Antioxidants and lipid peroxidation status in the blood of patients with psoriasis," Clinica Chimica Acta, vol. 289, no. 1-2, pp. 23-31, 1999.

[93] M. Naziroglu and I. Kokcam, "Antioxidants and lipid peroxidation status in the blood of patients with alopecia," Cell Biochemistry and Function, vol. 18, no. 3, pp. 169-173, 2000.

[94] S. M. Lynch, A. L. Campione, and M. K. Moore, "Plasma thiols inhibit hemin-dependent oxidation of human lowdensity lipoprotein," Biochimica et Biophysica Acta, vol. 1485, no. 1, pp. 11-22, 2000.

[95] J. Thambyrajah and J. N. Townend, "Homocysteine and atherothrombosis-mechanisms for injury," European Heart Journal, vol. 21, no. 12, pp. 967-974, 2000.

[96] B. Vanizor Kural, A. Örem, G. Çimşit, H. A. Uydu, Y. E. Yandi, and A. Alver, "Plasma homocysteine and its relationships with atherothrombotic markers in psoriatic patients," Clinica Chimica Acta, vol. 332, no. 1-2, pp. 23-30, 2003.

[97] D. Peus, A. Beyerle, H. L. Rittner et al., "Anti-psoriatic drug anthralin activates JNK via lipid peroxidation: mononuclear cells are more sensitive than keratinocytes," Journal of Investigative Dermatology, vol. 114, no. 4, pp. 688-692, 2000.

[98] M. Westergaard, J. Henningsen, C. Johansen et al., "Expression and localization of peroxisome proliferator-activated receptors and nuclear factor $\kappa \mathrm{B}$ in normal and lesional psoriatic skin," Journal of Investigative Dermatology, vol. 121, no. 5, pp. 1104-1117, 2003.

[99] D. A. Plager, A. A. Leontovich, S. A. Henke et al., "Early cutaneous gene transcription changes in adult atopic dermatitis and potential clinical implications," Experimental Dermatology, vol. 16, no. 1, pp. 28-36, 2007.

[100] M. Schmuth, Y. J. Jiang, S. Dubrac, P. M. Elias, and K. R. Feingold, "Peroxisome proliferator-activated receptors and liver X receptors in epidermal biology," Journal of Lipid Research, vol. 49, no. 3, pp. 499-509, 2008.

[101] D. M. Sommer, S. Jenisch, M. Suchan, E. Christophers, and M. Weichenthal, "Increased prevalence of the metabolic syndrome in patients with moderate to severe psoriasis," Archives of Dermatological Research, vol. 298, no. 7, pp. 321328, 2006.

[102] M.-H. Tan, M. Gordon, O. Lebwohl, J. George, and M. G. Lebwohl, "Improvement of pyoderma gangrenosum and psoriasis associated with Crohn disease with anti-tumor necrosis factor $\alpha$ monoclonal antibody," Archives of Dermatology, vol. 137, no. 7, pp. 930-933, 2001.

[103] M. Schmuth, C. M. Haqq, W. J. Cairns et al., "Peroxisome proliferator-activated receptor (PPAR)- $\beta / \delta$ stimulates differentiation and lipid accumulation in keratinocytes," Journal of Investigative Dermatology, vol. 122, no. 4, pp. 971-983, 2004.

[104] M. Q. M. Man, E.-H. Choi, M. Schmuth et al., "Basis for improved permeability barrier homeostasis induced by PPAR and LXR activators: liposensors stimulate lipid synthesis, lamellar body secretion, and post-secretory lipid processing," Journal of Investigative Dermatology, vol. 126, no. 2, pp. 386392, 2006.

[105] S. Dubrac, P. Stoitzner, D. Pirkebner et al., "Peroxisome proliferator-activated receptor- $\alpha$ activation inhibits Langerhans cell function," Journal of Immunology, vol. 178, no. 7, pp. 4362-4372, 2007.

[106] A. J. Fowler, M. Y. Sheu, M. Schmuth et al., "Liver X receptor activators display anti-inflammatory activity in irritant and allergic contact dermatitis models: liver-X-receptor-specific inhibition of inflammation and primary cytokine production," Journal of Investigative Dermatology, vol. 120, no. 2, pp. 246-255, 2003. 
[107] S. B. Joseph, A. Castrillo, B. A. Laffitte, D. J. Mangelsdorf, and P. Tontonoz, "Reciprocal regulation of inflammation and lipid metabolism by liver X receptors," Nature Medicine, vol. 9, no. 2, pp. 213-219, 2003.

[108] C. N. Ellis, J. Varani, G. J. Fisher et al., "Troglitazone improves psoriasis and normalizes models of proliferative skin disease: ligands for peroxisome proliferator-activated receptor- $\gamma$ inhibit keratinocyte proliferation," Archives of Dermatology, vol. 136, no. 5, pp. 609-616, 2000.

[109] H. A. Pershadsingh, S. C. Benson, and C. N. Ellis, "Improvement in psoriasis with rosiglitazone in a diabetic and a nondiabetic patient," Skinmed, vol. 4, no. 6, pp. 386-390, 2005.

[110] T. Bongartz, B. Coras, T. Vogt, J. Schölmerich, and U. Müller-Ladner, "Treatment of active psoriatic arthritis with the PPAR $\gamma$ ligand pioglitazone: an open-label pilot study," Rheumatology, vol. 44, no. 1, pp. 126-129, 2005.

[111] H. Robertshaw and P. S. Friedmann, "Pioglitazone: a promising therapy for psoriasis," British Journal of Dermatology, vol. 152, no. 1, pp. 189-191, 2005.

[112] N. Shafiq, S. Malhotra, P. Pandhi, M. Gupta, B. Kumar, and K. Sandhu, "Pilot trial: pioglitazone versus placebo in patients with plaque psoriasis (the P6)," International Journal of Dermatology, vol. 44, no. 4, pp. 328-333, 2005.

[113] S. Kuenzli and J.-H. Saurat, "Effect of topical PPAR $\beta / \delta$ and PPAR $y$ agonists on plaque psoriasis: a pilot study," Dermatology, vol. 206, no. 3, pp. 252-256, 2003.

[114] S. Kuenzli and J.-H. Saurat, "Peroxisome proliferatoractivated receptors as new molecular targets in psoriasis," Current Drug Targets: Inflammation \& Allergy, vol. 3, no. 2, pp. 205-211, 2004.

[115] M. Denda, L. C. Wood, S. Emami et al., "The epidermal hyperplasia associated with repeated barrier disruption by acetone treatment or tape stripping cannot be attributed to increased water loss," Archives of Dermatological Research, vol. 288, no. 5-6, pp. 230-238, 1996.

[116] L. Piqueras, A. R. Reynolds, K. M. Hodivala-Dilke et al., "Activation of PPAR $\beta / \delta$ induces endothelial cell proliferation and angiogenesis," Arteriosclerosis, Thrombosis, and Vascular Biology, vol. 27, no. 1, pp. 63-69, 2007.

[117] S. G. Harris and R. P. Phipps, "Induction of apoptosis in mouse $\mathrm{T}$ cells upon peroxisome proliferator-activated receptor gamma (PPAR- $\gamma$ ) binding," Advances in Experimental Medicine and Biology, vol. 507, pp. 421-425, 2002.

[118] S. Kuenzli and J.-H. Saurat, "Peroxisome proliferatoractivated receptors in cutaneous biology," British Journal of Dermatology, vol. 149, no. 2, pp. 229-236, 2003.

[119] S. Malhotra, D. Bansal, N. Shafiq, P. Pandhi, and B. Kumar, "Potential therapeutic role of peroxisome proliferator activated receptor- $\gamma$ agonists in psoriasis," Expert Opinion on Pharmacotherapy, vol. 6, no. 9, pp. 1455-1461, 2005.

[120] L. G. Kömüves, M. Schmuth, A. J. Fowler et al., "Oxysterol stimulation of epidermal differentiation is mediated by liver $\mathrm{X}$ receptor- $\beta$ in murine epidermis," Journal of Investigative Dermatology, vol. 118, no. 1, pp. 25-34, 2002.

[121] H. Yalcin, D. D. Balci, E. Ucar et al., "Myocardial perfusion is preserved in patients with psoriasis without clinically evident cardiovascular disease," Journal of the European Academy of Dermatology and Venereology, vol. 23, no. 7, pp. 798-802, 2009.

[122] Y. B. Brauchli, S. S. Jick, M. Miret, and C. R. Meier, "Psoriasis and risk of incident myocardial infarction, stroke or transient ischaemic attack: an inception cohort study with a nested case-control analysis," British Journal of Dermatology, vol. 160, no. 5, pp. 1048-1056, 2009.

[123] M. Mastrolonardo, A. Picardi, D. Alicino, A. Bellomo, and P. Pasquini, "Cardiovascular reactivity to experimental stress in psoriasis: a controlled investigation," Acta DermatoVenereologica, vol. 86, no. 4, pp. 340-344, 2006.

[124] M. J. Kaplan, "Cardiometabolic risk in psoriasis: differential effects of biologic agents," Vascular Health and Risk Management, vol. 4, no. 6, pp. 1229-1235, 2008.

[125] R. S. Azfar and J. M. Gelfand, "Psoriasis and metabolic disease: epidemiology and pathophysiology," Current Opinion in Rheumatology, vol. 20, no. 4, pp. 416-422, 2008.

[126] H. M. Kremers, M. T. McEvoy, F. J. Dann, and S. E. Gabriel, "Heart disease in psoriasis," Journal of the American Academy of Dermatology, vol. 57, no. 2, pp. 347-354, 2007.

[127] P. Gisondi, F. Fantin, M. Del Giglio et al., "Chronic plaque psoriasis is associated with increased arterial stiffness," Dermatology, vol. 218, no. 2, pp. 110-113, 2009.

[128] J. Dreiher, D. Weitzman, J. Shapiro, B. Davidovici, and A. D. Cohen, "Psoriasis and chronic obstructive pulmonary disease: a case-control study," British Journal of Dermatology, vol. 159, no. 4, pp. 956-960, 2008.

[129] J. M. Gelfand, A. L. Neimann, D. B. Shin, X. Wang, D. J. Margolis, and A. B. Troxel, "Risk of myocardial infarction in patients with psoriasis," Journal of the American Medical Association, vol. 296, no. 14, pp. 1735-1741, 2006.

[130] M. D. Herron, M. Hinckley, M. S. Hoffman et al., "Impact of obesity and smoking on psoriasis presentation and management," Archives of Dermatology, vol. 141, no. 12, pp. 1527-1534, 2005.

[131] C. Huerta, E. Rivero, and L. A. García Rodríguez, "Incidence and risk factors for psoriasis in the general population," Archives of Dermatology, vol. 143, no. 12, pp. 1559-1565, 2007.

[132] J. A. Kaye, L. Li, and S. S. Jick, "Incidence of risk factors for myocardial infarction and other vascular diseases in patients with psoriasis," British Journal of Dermatology, vol. 159, no. 4, pp. 895-902, 2008.

[133] R. J. Ludwig, C. Herzog, A. Rostock et al., "Psoriasis: a possible risk factor for development of coronary artery calcification," British Journal of Dermatology, vol. 156, no. 2, pp. 271-276, 2007.

[134] A. L. Neimann, D. B. Shin, X. Wang, D. J. Margolis, A. B. Troxel, and J. M. Gelfand, "Prevalence of cardiovascular risk factors in patients with psoriasis," Journal of the American Academy of Dermatology, vol. 55, no. 5, pp. 829-835, 2006.

[135] J. M. Gelfand, E. D. Dommasch, D. B. Shin et al., "The risk of stroke in patients with psoriasis," Journal of Investigative Dermatology, vol. 129, no. 10, pp. 2411-2418, 2009.

[136] W. Koenig, "Predicting risk and treatment benefit in atherosclerosis: the role of C-reactive protein," International Journal of Cardiology, vol. 98, no. 2, pp. 199-206, 2005.

[137] S. Corbetta, R. Angioni, A. Cattaneo, P. Becke-Peccoz, and A. Spada, "Effects of retinoid therapy on insulin sensitivity, lipid profile and circulating adipocytokines," European Journal of Endocrinology, vol. 154, no. 1, pp. 83-86, 2006.

[138] A. K. Gupta, M. T. Goldfarb, C. N. Ellis, and J. V. Voorhees, "Side-effect profile of acitretin therapy in psoriasis," Journal of the American Academy of Dermatology, vol. 20, no. 6, pp. 1088-1093, 1989.

[139] A. Vahlquist and H. Törmä, "Retinoids and keratinization. Current concepts," International Journal of Dermatology, vol. 27, no. 2, pp. 81-95, 1988. 
[140] C. N. Ellis, S. Kang, A. I. Vinik, et al., "Glucose and insulin responses are improved in patients with psoriasis during therapy with etretinate," Archives of Dermatology, vol. 123, no. 4, pp. 471-475, 1987.

[141] T. Ohtsuka, "The correlation between response to oral cyclosporin therapy and systemic inflammation, metabolic abnormality in patients with psoriasis," Archives of Dermatological Research, vol. 300, no. 10, pp. 545-550, 2008.

[142] B. E. Strober and K. Menon, "Folate supplementation during methotrexate therapy for patients with psoriasis," Journal of the American Academy of Dermatology, vol. 53, no. 4, pp. 652659, 2005.

[143] M. Soy, M. Yildiz, M. S. Uyanik, N. Karaca, G. Güfer, and S. Piskin, "Susceptibility to atherosclerosis in patients with psoriasis and psoriatic arthritis as determined by carotidfemoral (aortic) pulse-wave velocity measurement," Revista Española de Cardiología, vol. 62, no. 1, pp. 96-99, 2009.

[144] Y. Gunes, M. Tuncer, O. Calka et al., "Increased frequency of pulmonary hypertension in psoriasis patients," Archives of Dermatological Research, vol. 300, no. 8, pp. 435-440, 2008.

[145] A. Pietrzak, M. Borowik, G. Chodorowska, et al., "Lipid profile and serum NT-proBNP level, and disease adaptation in psoriatic patients," in Sick Person-Biopsychosocial Aspects, K. Janowski and J. Gierus, Eds., pp. 348-360, Wydawnictwo Drukarnia Best Print s.c., Lublin, Poland, 2009.

[146] J. Wysocki, S. Skoczyński, A. Strózik, B. Hochuł, and M. Zyguła, "Metabolic or immunometabolic syndrome?" Wiadomosci Lekarskie, vol. 58, no. 1-2, pp. 124-127, 2005.

[147] A. Zalewska, E. Głowacka, J. Wyczółkowska, H. Tchórzewski, J. Narbutt, and A. Sysa-Jědrzejowska, "Interleukin 6 and 8 levels in plasma and fibroblast cultures in psoriasis," Mediators of Inflammation, vol. 2006, Article ID 81767, 6 pages, 2006.

[148] B. D. Edwards, D. Bhatnagar, M. I. Mackness et al., "Effect of low-dose cyclosporin on plasma lipoproteins and markers of cholestasis in patients with psoriasis," Quarterly Journal of Medicine, vol. 88, no. 2, pp. 109-113, 1995.

[149] A. Lassus, A.-L. Dahlgren, M. J. Halpern, J. Santalahti, and H.-P. Happonen, "Effects of dietary supplementation with polyunsaturated ethyl ester lipids (Angiosan) in patients with psoriasis and psoriatic arthritis," Journal of International Medical Research, vol. 18, no. 1, pp. 68-73, 1990.

[150] H. Meffert, M. Bräutigam, L. Färber, and G. Weidinger, "Low-dose $(1.25 \mathrm{mg} / \mathrm{kg})$ cyclosporin A: treatment of psoriasis and investigation of the influence on lipid profile," Acta Dermato-Venereologica, vol. 77, no. 2, pp. 137-141, 1997.

[151] J. Miquel, A. Bernd, J. Sempere, J. Díaz-Alperi, and A. Ramírez, "The curcuma antioxidants: pharmacological effects and prospects for future clinical use. A review," Archives of Gerontology and Geriatrics, vol. 34, no. 1, pp. 3746, 2002.

[152] A. Osmancevic, L. Nilsen, K. Landin-Wilhelmsen et al., "Effect of climate therapy at Gran Canaria on vitamin D production, blood glucose and lipids in patients with psoriasis," Journal of the European Academy of Dermatology and Venereology, vol. 23, no. 10, pp. 1133-1140, 2009.

[153] F. Reiss and L. Jaimovich, "The influence of sitosterol upon psoriasis vulgaris: observations on electrophoretic pattern," Dermatologica, vol. 17, no. 5, pp. 393-401, 1958.

[154] N. Sattar, P. Crompton, L. Cherry, D. Kane, G. Lowe, and I. B. McInnes, "Effects of tumor necrosis factor blockade on cardiovascular risk factors in psoriatic arthritis: a doubleblind, placebo-controlled study," Arthritis and Rheumatism, vol. 56, no. 3, pp. 831-839, 2007.
[155] G. Vallesi, F. Raggi, S. Rufini, S. Gizzi, E. Ercolani, and R. Rossi, "Effects of cyclotronic ion resonance on human metabolic processes: a clinical trial and one case report," Electromagnetic Biology and Medicine, vol. 26, no. 4, pp. 283$288,2007$.

[156] I. V. Shrinsky and V. S. Shrinskt, "Efficacy of simvastin in plaque psoriasis: a pilot study," The Journal of American Academy of Dermatology, vol. 57, no. 3, pp. 529-531, 2007.

[157] J. M. Ashley, N. J. Lowe, M. E. Borok, and R. B. Alfin-Slater, "Fish oil supplementation results in decreased hypertriglyceridemia in patients with psoriasis undergoing etretinate or acitretin therapy," Journal of the American Academy of Dermatology, vol. 19, no. 1 I, pp. 76-82, 1988.

[158] J. R. Marsden, "Effect of dietary fish oil on hyperlipidaemia due to isotretinoin and etretinate," Human Toxicology, vol. 6, no. 3, pp. 219-222, 1987.

[159] R. M. Grossman, R. J. Delaney, E. A. Brinton, D. M. Carter, and A. B. Gottlieb, "Hypertriglyceridemia in patients with psoriasis treated with cyclosporine," Journal of the American Academy of Dermatology, vol. 25, no. 4, pp. 648-651, 1991.

[160] E. Cauza, K. Cauza, U. Hanusch-Enserer, M. Etemad, A. Dunky, and K. Kostner, "Intravenous anti TNF- $\alpha$ antibody therapy leads to elevated triglyceride and reduced HDLcholesterol levels in patients with rheumatoid and psoriatic arthritis," Wiener Klinische Wochenschrift, vol. 114, no. 23-24, pp. 1004-1007, 2002.

[161] C. Antoniou, C. Dessinioti, A. Katsambas, and A. J. Stratigos, "Elevated triglyceride and cholesterol levels after intravenous antitumour necrosis factor- $\alpha$ therapy in a patient with psoriatic arthritis and psoriasis vulgaris," British Journal of Dermatology, vol. 156, no. 5, pp. 1090-1091, 2007.

[162] E. Spanakis, P. Sidiropoulos, J. Papadakis et al., "Modest but sustained increase of serum high density lipoprotein cholesterol levels in patients with inflammatory arthritides treated with infliximab," Journal of Rheumatology, vol. 33, no. 12, pp. 2440-2446, 2006.

[163] A. N. Rajpara, R. Goldner, and A. Gaspari, "Psoriasis: can statins play a dual role?" Dermatology Online Journal, vol. 16, no. 2, article 2, 2010.

[164] T. C. Jacobi and A. Highet, "A clinical dilemma while treating hypercholesterolaemia in psoriasis," British Journal of Dermatology, vol. 149, no. 6, pp. 1305-1306, 2003. 


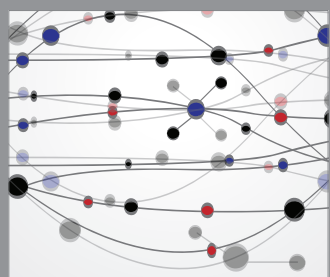

The Scientific World Journal
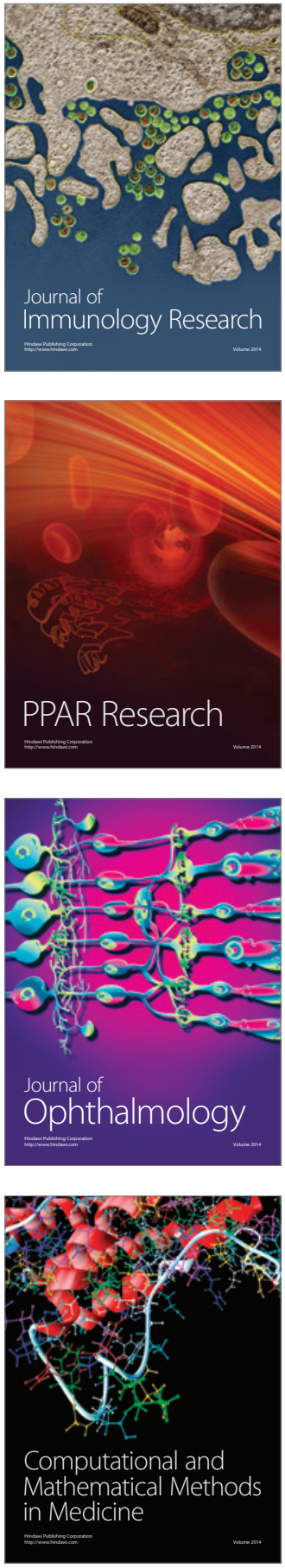

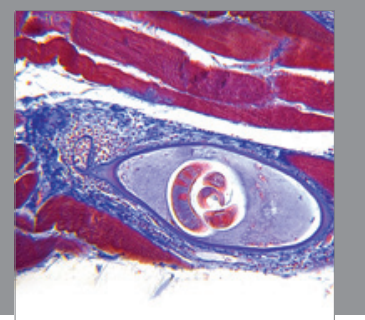

Gastroenterology

Research and Practice
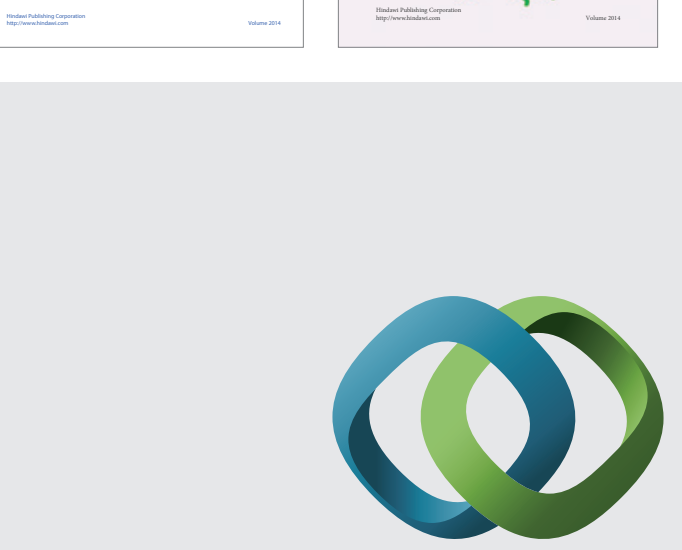

\section{Hindawi}

Submit your manuscripts at

http://www.hindawi.com
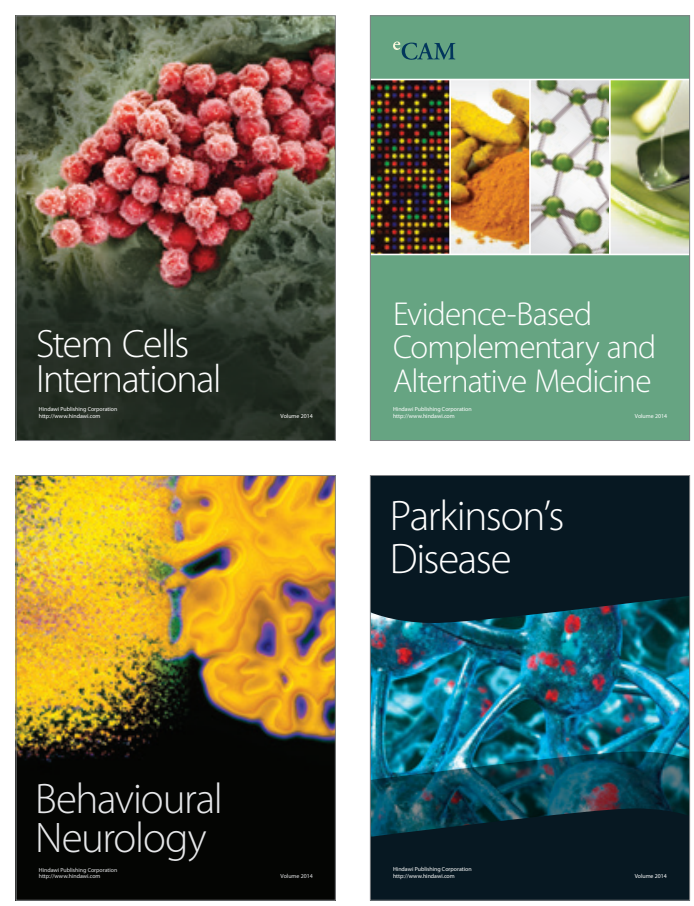

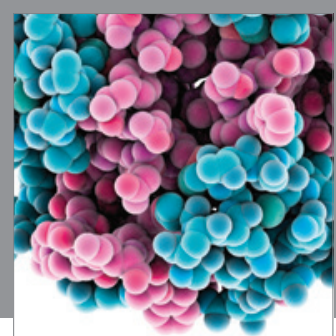

Journal of
Diabetes Research

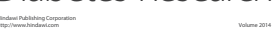

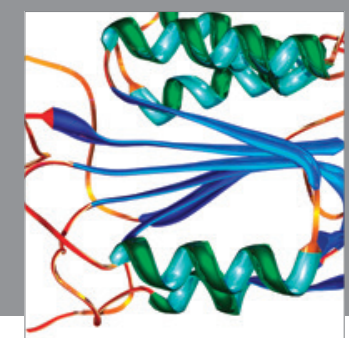

Disease Markers
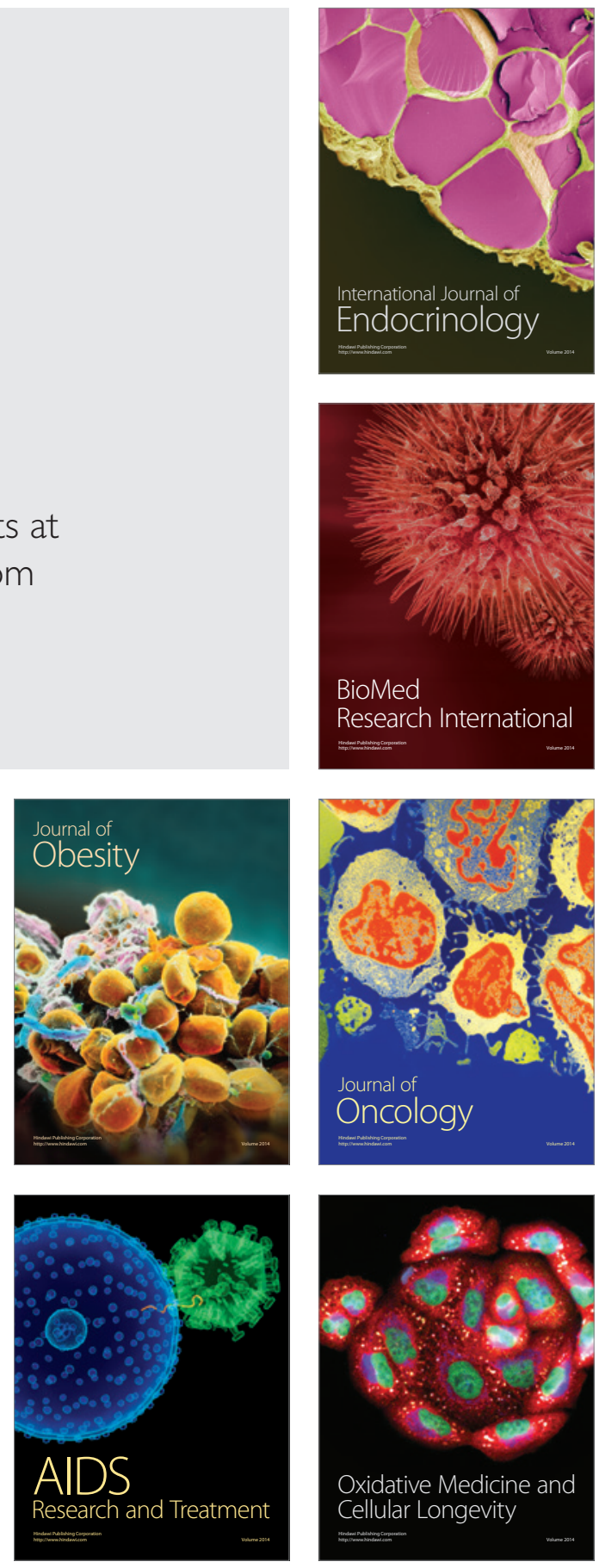